1

2

3

5

6

7

8

\title{
Survival Analysis and Prognostic Factors of Time to First Domestic Violence after Marriage among Married Women in Africa
}

Fagbamigbe, A. F. ${ }^{*}$, Akintayo, A. O. ${ }^{1}$, Oshodi, O. ${ }^{1}$, Makinde, F. T. ${ }^{1}$, Babalola, M. ${ }^{1}$, Damilola, E. A. ${ }^{1}$ \& Enabor, O. C. ${ }^{1}$

${ }^{1}$ Department of Epidemiology and Medical Statistics, Faculty of Public Health, College of Medicine, University of Ibadan, Nigeria

*Corresponding author; fadenivi@cartafrica.org 


\section{Survival Analysis and Prognostic Factors of Time to First Domestic Violence after Marriage among Married Women in Africa}

\section{ABSTRACT}

Background: Domestic violence remains a public health challenge worldwide. Studies in the subSaharan Africa have shown high level of violence against women, especially from intimate partners. What is not known is how soon domestic violence happens after marriage among evermarried women. This study assessed the timing of first domestic violence among ever-married women and identified its determinants in Nigeria, Kenya, and Mozambique.

Data and Method: Data of 56440 ever-married women of reproductive age pooled from DHS conducted in Nigeria (2013), Kenya (2014) and Mozambique (2011) was used. The timing of first domestic violence was estimated as the period between marriage and the first experience of domestic violence. Ever-married women without violence experience were censored on the date of the survey. Survival analysis techniques were used to assess the timing and the factors influencing the timing $\mathrm{p}=0.05$.

Result: The prevalence of domestic violence in Nigeria, Kenya and Mozambique was $12.1 \%$, $7.5 \%$, and $15.4 \%$ respectively. The median time to first domestic violence across the three countries was 3 years. We found a higher prevalence of violence among formerly married women than currently married women. Women who married before age 20 years have a significantly higher risk of experiencing violence (Nigeria: $\mathrm{aHR}=2.36(95 \% \mathrm{CI}(1.97-2.83)$, Kenya: $\mathrm{aHR}=1.89$ (95\% CI (1.31- 2.73) and Mozambique: aHR=1.60 (95\% CI (1.24 -2.12)) than older women. Women in poorer wealth quintile were at higher risk of violence across the three countries. Other factors associated with the timing of first domestic violence are respondents', location of residence and educational attainment. 
32 Conclusion: Domestic violence has remained high in Mozambique, Nigeria and Kenya. There was a significant relationship between timing of first domestic violence and whether or not a woman remains in a marriage. Education and delayed marriage could help reduce violence in marriage.

Keywords: Violence, marriage, domestic, education, marital status, Africa,

\section{BACKGROUND}

Violence is a fundamental human right issue and has constituted global social, clinical health as well as public health challenges(1-4). Literature is replete that violence against women, especially women and girls has remained high despite several interventions to halt it $(5,6)$. Depending on the presence or absence of a relationship between a victim and a perpetrator of a violence, violence can be grouped as self-directed, interpersonal and collective violence. Domestic violence is one of the interpersonal violence and has unacceptably thrived across various regions of the world. Domestic violence, also referred to as spousal or intimate partner violence, is a subtle type of

45 violence occurring between partners in union (legal or not) and within the family context. Domestic violence happens both in cohabitation and marriage. Nevertheless, occurrence may not

47 be restricted to the confines of the home(3). Domestic violence is not peculiar to only

48 heterosexuals, it occurs in both same and different-sex marriages and is perpetrated by both men

49 and women. However, research has overtime revealed that domestic violence are mostly 50 perpetrated by men against the women.

51 Despite the development of gender policy in Nigeria and other African countries to promote the 52 health and protect the rights of women, domestic violence remains a menace to the health and 53 wellbeing of African women(7). This is fostered among other factors by unhealthy sociocultural 54 norms that presupposes African women as inferior to men(8). Sadly, significant proportion of 
women in Africa hold perceptions which justify physical assault of a woman by her husband or

partner, thereby encouraging under-reporting of spousal violence. The level of domestic violence

57 in Kenya has been established by various studies with physical violence and sexual prevalence

58 placed at $42 \%$ and $14 \%$ respectively. The figures lie in the middle range of the WHO multi-country

59 estimate $14-61 \%$ and $6-59 \%$ respectively $(9,10)$.

60 The prevalence of domestic violence is diverse across different settings. While ample evidence

61 exists that supports the occurrence of domestic violence across the world, disparity exists in its

62 prevalence among low and middle income countries (LMIC) as well as high income countries. For

63 instance, $15 \%$ to $71 \%$ of ever-married women have been reported to have been abused either

64 physically or sexually by an intimate partner throughout at some points in their lives(11). In a

65 multi-regional study carried out by WHO, the prevalence of lifetime sexual and/or physical spousal

66 violence among ever-married women was 30\%. The highest prevalence was found in the low and

67 middle income countries among ever-married women in the WHO South-East Asia, Eastern

68 Mediterranean and African regions (37.7\%, 37.0\% and 36.6\%) compared to 23.2\% in high income

69 countries(10).

70

71

72

73

74

75

76
Multiple studies have reported increased occurrence of violence against women in the sub-Saharan Africa region, particularly in Nigeria which is the largest country in Africa(12-14). A recent study found a prevalence of spousal violence (physical, sexual or emotional) of about $30.5 \%$ in Nigeria 45.3\% in Kenya and 45.5\% in Mozambique(4). In a meta-analysis of 141 studies conducted in 81 countries the frequency of lifetime exposure to domestic violence among women was found to be relatively high with $65.6 \%$ in central sub-Saharan Africa, western sub-Saharan Africa (41.8\%) and South Asia (41.7\%)(15). 
77 The consequence of domestic violence on women is quite colossal. Women's sexual and

78 reproductive health suffers incessant denting(16). Besides maternal depletion disorder in

79 conjunction with its associated problems, research has shown that inadvertent pregnancy

80 termination can also be linked to domestic violence among married persons $(8,17)$. Furthermore,

81 research in the past decades has provided sufficient evidence that suicide, homicide, physical

82 injuries, increased susceptibility to sexually transmitted infections, unwanted pregnancies, forced

83 abortion, gynecological complaints, low body mass index infant and child mortality are possible

84 adverse effects of spousal violence on women's reproductive health(5,7,18-21). Physical and

85 sexual violence by partner has been linked with increased transmission of HIV among Kenyan

women via tears and laceration of the vaginal canal(22,23). In Nigeria, domestic violence has been

87 linked to an increase in the incidence of miscarriages, induced abortions and stillbirths(24).

Literature have identified risk factors of domestic violence to include age at marriage or cohabitation, religion, education, place of residence and household wealth quintile and employment $(4,10,12,19)$. A recent multi-regional study by WHO showed that the prevalence of domestic violence among ever-married women was about $29.4 \%$ in women aged 15-19 years, suggesting that IPV starts early in life, but higher (over 36\%) among older women(10). Another multi-country study in sub-Saharan Africa linked higher prevalence of violence to higher household wealth quintile in Mozambique while the reverse was the case for Kenya as women from poor households were reported to be more probable suffer domestic violence(4).

While the differential pattern and distribution of domestic violence among married and cohabiting women has been evaluated(4,25-29), the timing of the occurrence of first domestic violence has not been explored in sub-Saharan Africa. Similarly, study outcomes abound on the prevalence of domestic violence and the factors influencing it(4,26-29), but there remains no information on the 
100 factors that could affect the risk and the time to first domestic violence among ever-married women

101 in sub-Saharan Africa. The current study is therefore designed to assess how long it takes married

102 women in Nigeria, Kenya and Mozambique Africa to first experience domestic violence and also

103 to identify the risk factors of the timing. Considerably, new insights provided by this paper would

104 be useful for effective intervention against spousal abuse in Nigeria, Kenya and Mozambique and

105 possibly sub-Saharan Africa.

Materials and Methods

107 Study Setting

108 This study used data from the most recent sets of Demographic and Health Survey (DHS) 109 conducted in Nigeria (2013), Kenya (2014), and Mozambique (2011) conducted by ICF Macro

110 Calverton, Maryland, USA in conjunction with Population Councils of three different African

111 countries. All the DHSs were cross-sectional and nationally representative. The surveys used the

112 same set of questions to obtain information on demographics, sexuality and other reproductive and

113 sexual behavior of men and women of reproductive age. All the DHS used in this study provided

114 population and health indicator estimates at the national and provincial/district/state levels.

\section{Sampling and Samples}

\section{$116 \quad$ Nigeria}

117 The Nigeria DHS 2013 adopted probability multistage sampling procedure to select representative 118 sample of women. The sampling used the enumeration areas (EA) that were prepared from the 1192006 population census of Nigeria as primary sampling units. The sample was selected using a 120 stratified three-stage cluster design consisting of 904 clusters - 372 in urban areas and 532 in rural 
121 areas. At the first stage, local governments were selected, then EAs were selected at the second

122 stage while the households were selected at the third stage. A representative sample of 40680

123 households was selected for the survey among which 38948 were successfully interviewed.

124 Detailed sampling details have been documented (30).

\section{Kenya}

126 The sample for the 2014 Kenya DHS was drawn from the Fifth National Sample Survey, and

127 Evaluation Programme (NASSEP-V). Kenya is divided into 47 counties with each county stratified

128 into urban and rural strata (clusters). Using a two-stage sampling design, samples were drawn in

129 each stratum independent of other strata. In the first stage, 1612 clusters were randomly selected

130 with equal probability selection method from the NASSEP-V frame, with 617 from urban and 995

131 from rural areas. Twenty-five households were randomly selected from each cluster using the list

132 of eligible households at the second stage. A total of 40,300 households were visited among which

13331,079 women were interviewed.

\section{Mozambique}

135 The sample for the 2011 Mozambique DHS was selected from the 11 provinces in the country.

136 Each province was divided in districts, and the districts further subdivided into administrative posts

137 using the master sample designed by the National Statistical Office and the US Census Bureau

138 using the 1997 household and population census. A representative probability sample of

139 approximately 14,500 households was selected for the 2011 MDHS among which 13745 were

140 successfully interviewed. Samples of districts were drawn at the first stage within each district,

141 samples of administrative polls drawn at the second stage from the selected districts, while the

142 EAs and the households were subsequently drawn at the $3^{\text {rd }}$ and $4^{\text {th }}$ stages. 


\section{Sampling of respondents on Violence related questions}

144 Due to the sensitivity of violence and to maintain confidentiality, only one woman per household

145 was administered the questions on violence while. In the one-third of the households selected for

146 the male survey, one man per household was randomly selected to respond to questions on

147 domestic violence. One woman per household was randomly selected in the remaining two-thirds

148 of households and were administered the questions on violence. The selected respondents were

149 informed that questions could be sensitive and were reassured regarding the confidentiality of their

150 responses.

151 Data

152 To determine whether an ever-married woman had experienced domestic violence prior to the

153 survey dates, the following questions were asked. Were you: ever been pushed, shook or had

154 something thrown by husband/partner, ever been slapped by husband/partner, ever had arm twisted

155 or hair pulled by husband/partner; ever been punched with fist or hit by something harmful by

156 husband/partner, ever been kicked or dragged by husband/partner; ever been strangled or burnt by

157 husband/partner ever been threatened with knife/gun or other weapon by husband/partner; ever

158 been physically forced into unwanted sex by husband/partner; ever been forced into other

159 unwanted, sexual acts by husband/partner; ever been physically forced to perform sexual acts

160 respondent didn't want to.

161 Any ever-married who answered in affirmative to at least one of the question is considered to have

162 experienced domestic violence and were then asked how long was the first time they experienced

163 any form of these violence after they got married. The length of time between marriage date and

164 the date of first domestic violence was used as the dependent variable in this study while age, 
165 education, employment, residence and wealth indicators were used as independent variable. They

166 have been identified in prior studies as contributing factors to domestic violence among

$167 \operatorname{women}(4,10,12,19)$.

\section{Inclusion and exclusion criteria}

169 The current study focused on experience of domestic violence among ever-married women. We

170 therefore excluded never married women either they were living with sexual partner or not. Only

171 women aged 15-49 years and who were currently married, divorced, separated or widowed were

172 included in the analysis. The effective sampling size for this study was 21,564, 4,237, and 3992

173 for Nigeria, Kenya and Mozambique respectively totaling 29,793 respondents. Of the 6440 that

174 claimed to have experienced violence before, 343 did not remember their time of first experience

175 after marriage, they were therefore excluded in further analysis except in Table 1.

\section{Data Analysis}

177 Descriptive statistics and survival analysis techniques were used to analyze the data at a $5 \%$

178 significance level. Cox proportional hazard regression model was used to identify the risk factors

179 associated with the timings. All data were weighed so as to ensure adequate representativeness at

180 the national, regional, and county levels because of the non-proportional allocation to the sampling

181 strata and the fixed sample size per cluster. The statistical analysis was carried out using IBM

182 SPSS 24.

\section{Justification for use of Survival Analysis}

184 Right from the day of marriage, there are possibilities that an ever-married woman is violated by

185 her husband. However, it is not impossible that there are ever-married women without any 
experience of domestic violence as of the survey date. Non-inclusion of ever-married women who have not experience any domestic violence as of the day of the survey might seriously bias the computation of the timing of first domestic violence after marriage as well as its risk factor. The survival analysis remains the utmost data analysis procedure for lifetime data when some subjects have not experience the event of interest. Therefore, the populations at risk is all married women involved in the study. The duration from marriage to first domestic violence, ' $\mathrm{T}$ ', is assumed to be a discrete random variable that is always positive. The observation continues until time ' $t$ ', at which the event of interest (first domestic violence) occurs. The study ends for an individual at time ' $\mathrm{T}=\mathrm{t}$ ' if she experienced any form of domestic violence after marriage. Survival analysis requires the censoring index and the survival time as basic variables. The survival time is assumed to begin at the time a woman had her first marriage until the time she experienced first domestic violence after marriage. The survival time in our study is the length of time (years) between the date of marriage and the date of first domestic violence by the husband, for those who had experienced violence. For the women who did not experience any domestic violence as of survey date, the survival time is censored and the age of their marriage in years is used as their survival times.

The Kaplan Meier techniques were used to estimate survival and hazard functions. The survivor function is the probability that a woman survives longer than some specified time $t$ without experience any form of domestic violence, while the hazard function is the instantaneous potential per unit of time for domestic violence to occur, given that the woman had not experience any domestic violence before time t.

We used the Cox proportional-hazards to model risk factors of the timings and estimate the strength of the relationship between each of the selected independent variables and censored timing 
209 of first domestic violence. The outcomes of the model are the hazard ratios. A hazard ratio (HR)

$210<1$ means higher risk, $<1$ means lower risk while =1 suggest insignificantly different risk.

211 We tested whether the proportional-hazards assumption was violated using the significance of the

212 HRs and Wald $\chi 2$ statistics in our stratified Cox analysis. We moved the significant variables in

213 the bivariate Cox regression models into the multiple Cox regression to assess their association

214 with the outcome variable while controlling for confounders.

\section{RESULTS}

216 Table 1 shows the distribution of the ever-married women by their socio-demographic

217 characteristics and the prevalence of ever-experience of domestic violence across the three

218 countries. In all 89.8\% were currently married, almost a two-third (63.7\%) were from rural areas,

$21930.2 \%$ had had primary education, $31.2 \%$ were unemployed while $7.7 \%, 16.2 \%, 38.0 \%$, and $38.1 \%$

220 were aged 15-19, 20-24, 25-34 and 35-49 years respectively.

221 In Nigeria, 93.8\% of the ever-married women were currently married, about two-thirds $(62.8 \%)$

222 were from rural areas, almost half of the respondents $(47.10 \%)$ had had no formal education, while

$22398.8 \%$ were employed. Of the 4237 ever-married women in Kenya, 82.0\% were currently married,

224 about two-thirds $(60.5 \%)$ were from rural areas, more than half $(56.4 \%)$ had had primary education,

$22523.3 \%$ were not working, 2.8\%, 16.1\%, 43.8\%, and 37.3\% were aged 15-19, 20-24, 25-34 and 35-

22649 years respectively. Over 76\% ever-married women in Mozambique were currently married,

227 about two-thirds (69.3\%) were from rural areas, 50.8\% had had primary education, $48.7 \%$ were not

228 working while $10.9 \%, 19.2 \%, 35.6 \%$, and $34.3 \%$ were aged $15-19,20-24,25-34$ and $35-49$ years

229 respectively. 
Of the 29,793 ever-married women across the three countries, 6440 (21.3\%) reported ever experienced domestic violence. The prevalence of ever-experience of domestic violence was $15.4 \%, 39.0 \%$ and $31.0 \%$ in Nigeria, Kenya and Mozambique respectively. In Nigeria, the highest prevalence of domestic violence was among respondents aged 25-34 years (16.2\%), 35-49 years (16.1\%), 46.7\% among separated/divorced women, $24.1 \%$ among respondents with primary education, $17.2 \%$ among employed women, $27.9 \%$ among women who are older than their husbands, $37.0 \%$ among women whose husband takes alcohol and $19.5 \%$ among women whose husband get jealous when they talk to other men. Also, the highest report of domestic violence in Kenya was found among respondents aged 25-34 years (38.8\%), 35-49 years (41.4\%), 61.4\% among separated/divorced women, $44.0 \%$ among respondents with primary education, $43.0 \%$ among employed women, $35.8 \%$ among women who are of younger than their husbands, $54.7 \%$ among women whose husband takes alcohol and 52.3\% among women whose husband get jealous when they talk to other men. In Mozambique, the highest prevalence of domestic violence was among respondents aged 25-34 years (33.3\%), 20-24 years $(32.7 \%), 44.2 \%$ among separated/divorced women, $32.9 \%$ among respondents with primary education, $33.1 \%$ among employed women, $37.7 \%$ among women who are of same age as their husbands, $43.5 \%$ among women whose husband takes alcohol and 32.3\% among women whose husband get jealous when they talk to other men.

Table 1: Distribution of ever-married women by socio-demographic characteristics and violence experience across the selected countries

\begin{tabular}{|c|c|c|c|c|c|c|c|c|}
\hline \multirow{2}{*}{ Characteristics } & \multicolumn{4}{|c|}{ Distribution of Respondents (\%) } & \multicolumn{4}{|c|}{ Prevalence of Domestic Violence (\%) } \\
\hline & NIG & KEN & MOZ & All & NIG & KEN & MOZ & All \\
\hline \multicolumn{9}{|l|}{ Age } \\
\hline $\begin{array}{l}15-19 \\
20-24\end{array}$ & $\begin{array}{c}7.7 \\
15.5\end{array}$ & $\begin{array}{c}2.8 \\
16.1\end{array}$ & $\begin{array}{l}10.9 \\
19.2\end{array}$ & $\begin{array}{c}7.7 \\
1 \dot{6} .2\end{array}$ & $\begin{array}{c}9.3 \\
14.6\end{array}$ & $\begin{array}{l}22.4 \\
36.5\end{array}$ & $\begin{array}{l}22.6 \\
32.7\end{array}$ & $\begin{array}{l}13.4 \\
21.3\end{array}$ \\
\hline $25-34$ & 37.5 & 43.8 & 35.6 & 38.0 & 16.2 & 38.8 & 33.3 & 22.5 \\
\hline $35-49$ & 39.3 & 37.3 & 34.3 & 38.1 & 16.1 & 41.4 & 30.3 & 21.6 \\
\hline
\end{tabular}




\begin{tabular}{|c|c|c|c|c|c|c|c|c|}
\hline \multicolumn{9}{|l|}{ Marital Status } \\
\hline Currently Married & 93.8 & 82.0 & 76.4 & 89.8 & 14.0 & 36.1 & 25.7 & 18.0 \\
\hline Widowed & 3.4 & 5.8 & 7.0 & 4.2 & 17.5 & 42.7 & 24.0 & 23.6 \\
\hline Separated/Divorced & 2.8 & 12.2 & 16.6 & 6.0 & 46.7 & 61.4 & 44.2 & 49.8 \\
\hline \multicolumn{9}{|l|}{ Residence } \\
\hline Urban & 37.2 & 39.5 & 30.7 & 36.3 & 16.8 & 35.8 & 34.3 & 22.2 \\
\hline Rural & 62.8 & 60.5 & 69.3 & 63.7 & 14.5 & 41.0 & 29.5 & 20.8 \\
\hline \multicolumn{9}{|l|}{ Education } \\
\hline No education & 47.1 & 9.3 & 36.2 & 40.2 & 9.0 & 33.1 & 28.6 & 12.9 \\
\hline Primary & 19.7 & 56.4 & 50.8 & 30.2 & 24.1 & 44.0 & 32.9 & 31.7 \\
\hline Secondary & 28.8 & 26.0 & 12.0 & 23.3 & 21.4 & 35.2 & 30.4 & 24.3 \\
\hline Tertiary & 7.4 & 8.3 & 1.0 & 6.3 & 12.1 & 22.7 & 26.8 & 14.3 \\
\hline \multicolumn{9}{|l|}{ Husband education } \\
\hline No education & 39.1 & 7.5 & 24.9 & 32.5 & 8.46 & 37.1 & 29.4 & 12.1 \\
\hline Primary & 18.4 & 47.3 & 53.9 & 28.3 & 22.1 & 43.5 & 32.0 & 30.1 \\
\hline Secondary & 28.5 & 33.1 & 19.2 & 27.5 & 20.8 & 37.8 & 31.0 & 24.7 \\
\hline Tertiary & 14.0 & 12.2 & 2.0 & 11.7 & 15.1 & 26.3 & 20.8 & 16.7 \\
\hline \multicolumn{9}{|l|}{ Employment } \\
\hline Not employed & 28.1 & 23.3 & 48.7 & 31.2 & 10.8 & 25.2 & 28.7 & 17.2 \\
\hline Employed & 71.9 & 76.7 & 51.3 & 68.8 & 17.2 & 43.0 & 33.1 & 23.1 \\
\hline \multicolumn{9}{|l|}{ Husband employment } \\
\hline Not employed & 1.2 & 1.6 & 4.3 & 1.8 & 20.7 & 36.1 & 33.1 & 27.8 \\
\hline Employed & 98.8 & 98.4 & 95.7 & 98.2 & 15.3 & 39.1 & 30.9 & 21.2 \\
\hline \multicolumn{9}{|l|}{ Wealth Category } \\
\hline Poorest & 22.2 & 17.6 & 20.0 & 21.2 & 9.8 & 39.7 & 31.4 & 16.7 \\
\hline Poorer & 21.2 & 19.4 & 20.3 & 20.8 & 15.1 & 46.8 & 27.7 & 21.2 \\
\hline Middle & 18.5 & 18.9 & 21.2 & 19.1 & 19.4 & 42.5 & 29.8 & 24.5 \\
\hline Richest & 18.7 & 22.2 & 20.3 & 19.4 & 17.1 & 37.0 & 33.3 & 23.1 \\
\hline Richest & 19.4 & 21.9 & 18.2 & 19.5 & 16.7 & 30.8 & 33.1 & 21.4 \\
\hline \multicolumn{9}{|l|}{ Age difference } \\
\hline Wife Older & 1.0 & 3.0 & 5.6 & 2.0 & 27.9 & 30.3 & 22.2 & 25.7 \\
\hline Same age & 1.4 & 3.3 & 3.4 & 1.9 & 14.1 & 32.4 & 37.7 & 24.6 \\
\hline Wife younger & 97.6 & 93.7 & 91.0 & 96.1 & 14.3 & 35.8 & 29.6 & 19.2 \\
\hline \multicolumn{9}{|l|}{ Husband takes } \\
\hline No & 81.6 & 63.3 & 61.1 & 75.5 & 10.7 & 29.8 & 23.1 & 14.6 \\
\hline Yes & 18.4 & 36.7 & 38.9 & 24.5 & 37.0 & 54.7 & 43.5 & 42.4 \\
\hline \multicolumn{9}{|l|}{ Husband Jealous } \\
\hline No & 42.5 & 46.8 & 43.3 & 43.2 & 9.9 & 23.8 & 21.1 & 13.4 \\
\hline Yes & 57.5 & 53.2 & 56.7 & 56.8 & 19.5 & 52.3 & 32.3 & 27.3 \\
\hline Total & 21564 & 4237 & 3992 & 29793 & 15.4 & 39.0 & 31.0 & 21.3 \\
\hline
\end{tabular}

In Table 2, we present the distribution of timing of first domestic violence among ever-married

252 women who have already experienced the act. The median time to first domestic violence was 3

253 years in Nigeria and Kenya and 2 years in Mozambique. The timing varied across the women

254 characteristics. For instance, $29.6 \%$ of the currently married women in Nigeria experienced first

255 domestic violence within one year of marriage compared with 33.5\% among the separated/divorced

256 and $12.5 \%$ among the widows. In Mozambique, $48.0 \%$ of the currently married women experienced 
257 first domestic violence within one year of marriage compared with $49.3 \%$ among the 258 separated/divorced and 54.8\% among the widows within the same period.

259 The timing also appeared increased with women educational attainment, while the proportion of 260 women who experienced first domestic violence within one year of marriage among those that had

261 no education, primary, secondary and higher was $27.6 \%, 27.7 \%, 34.2 \%$, and $35.3 \%$ in Nigeria, the

262 figures were $31.9 \%, 29.0 \%, 32.4 \%$ and $46.9 \%$ in Kenya and $40.3 \%, 51.6 \%, 51.0 \%$ and $58.9 \%$ in

263 Mozambique. On the average, 30.4\% of ever-women in Nigeria, $30.9 \%$ in Kenya and $47.8 \%$ in

264 Mozambique had first domestic violence within one year of marriage.

Table 2: Distribution of time to first domestic violence after marriage among ever-married women in the three countries

\begin{tabular}{|c|c|c|c|c|c|c|c|c|c|c|c|c|}
\hline \multirow{3}{*}{ Characteristics } & \multicolumn{4}{|c|}{ Nigeria } & \multicolumn{4}{|c|}{ Kenya } & \multicolumn{4}{|c|}{ Mozambique } \\
\hline & \multirow{2}{*}{$\begin{array}{c}\text { Median } \\
\text { years } \\
\text { to FDV }\end{array}$} & \multicolumn{3}{|c|}{ Years to FDV (\%) } & \multirow{2}{*}{$\begin{array}{l}\text { Median } \\
\text { years } \\
\text { to FDV }\end{array}$} & \multicolumn{3}{|c|}{ Years to FDV (\%) } & \multirow{2}{*}{$\begin{array}{c}\text { Median } \\
\text { years } \\
\text { to FDV }\end{array}$} & \multicolumn{3}{|c|}{ Years to FDV (\%) } \\
\hline & & $<1$ & $2-3$ & $>3$ & & $<1$ & $2-3$ & $>3$ & & $<1$ & $2-3$ & $>3$ \\
\hline \multicolumn{13}{|l|}{ Age } \\
\hline $20-24$ & 1 & 56.0 & 29.8 & 14.2 & 2 & 55.7 & 31.0 & 13.3 & 1 & 61.6 & 27.3 & 11.0 \\
\hline $25-34$ & 3 & 30.0 & 36.2 & 33.8 & 3 & 32.6 & 34.6 & 32.8 & 2 & 44.2 & 36.0 & 19.8 \\
\hline $35-49$ & 4 & 16.7 & 27.1 & 56.2 & 4 & 17.2 & 27.2 & 55.7 & 3 & 36.8 & 28.8 & 34.4 \\
\hline \multicolumn{13}{|l|}{ Marital Status } \\
\hline Currently Married & 3 & 29.6 & 30.2 & 40.2 & 3 & 29.2 & 30.1 & 40.7 & 2 & 48.0 & 32.0 & 20.0 \\
\hline Widowed & 3 & 12.5 & 39.4 & 48.1 & 3 & 27.6 & 33.6 & 38.7 & 2 & 54.8 & 25.6 & 19.6 \\
\hline Separated/Divorced & 2 & 33.5 & 32.0 & 34.6 & 2 & 37.5 & 32.5 & 30.0 & 2 & 49.3 & 32.3 & 18.4 \\
\hline \multicolumn{13}{|l|}{ Residence } \\
\hline Urban & 3 & 26.7 & 34.3 & 39.0 & 2 & 36.8 & 31.0 & 32.2 & 2 & 51.6 & 27.2 & 21.2 \\
\hline Rural & 3 & 33.0 & 28.3 & 38.7 & 3 & 27.6 & 30.5 & 42.0 & 2 & 45.8 & 32.1 & 22.1 \\
\hline Education & 3 & & & & & & & & 2 & & & \\
\hline No education & 3 & 27.6 & 26.6 & 45.9 & 3 & 31.9 & 29.0 & 39.0 & 2 & 40.3 & 34.5 & 25.2 \\
\hline Primary & 3 & 27.7 & 29.9 & 42.4 & 3 & 29.0 & 31.6 & 39.4 & 2 & 51.6 & 28.0 & 20.4 \\
\hline Secondary & 3 & 34.2 & 35.1 & 30.7 & 3 & 32.4 & 30.2 & 37.5 & 2 & 51.0 & 30.4 & 18.6 \\
\hline Tertiary & 3 & 35.3 & 28.5 & 36.2 & 2 & 46.9 & 24.1 & 29.0 & 2 & 58.9 & 26.9 & 14.2 \\
\hline \multicolumn{13}{|l|}{ Husband education } \\
\hline No education & 3 & 25.7 & 26.3 & 48.0 & 2 & 29.5 & 29.1 & 41.4 & 2 & 44.5 & 29.5 & 25.9 \\
\hline Primary & 3 & 29.4 & 29.9 & 40.7 & 3 & 28.5 & 31.9 & 39.5 & 2 & 46.0 & 31.0 & 23.0 \\
\hline Secondary & 3 & 33.0 & 34.4 & 32.5 & 3 & 34.3 & 29.6 & 36.1 & 2 & 52.0 & 30.8 & 17.2 \\
\hline Tertiary & 3 & 32.7 & 28.2 & 39.2 & 3 & 35.8 & 28.2 & 36.0 & 2 & 60.1 & 27.4 & 12.5 \\
\hline \multicolumn{13}{|l|}{ Employment } \\
\hline Not employed & 2 & 39.9 & 27.8 & 32.2 & 2 & 31.6 & 36.3 & 32.1 & 2 & 52.9 & 27.1 & 19.9 \\
\hline Employed & 3 & 28.1 & 31.4 & 40.5 & 3 & 30.6 & 29.9 & 39.6 & 2 & 43.6 & 33.2 & 23.3 \\
\hline Husband & 3 & & & & & & & & & & & \\
\hline Not employed & 3 & 33.2 & 18.8 & 48.0 & 4 & 39.4 & 14.1 & 46.6 & 2 & 48.9 & 35.4 & 15.6 \\
\hline
\end{tabular}




\begin{tabular}{lllll|llll|llll} 
Employed & 3 & 30.4 & 30.9 & 38.7 & 3 & 30.7 & 31.0 & 38.3 & 2 & 47.7 & 30.2 & 22.1 \\
\hline Wealth Category & & & & & & & & & & & & \\
Poorest & 3 & 24.5 & 30.0 & 45.5 & 3 & 27.6 & 30.1 & 42.3 & 2 & 43.3 & 37.6 & 19.1 \\
Poorer & 3 & 32.4 & 28.9 & 38.8 & 3 & 28.8 & 32.8 & 38.4 & 2 & 46.7 & 30.1 & 23.2 \\
Middle & 3 & 33.9 & 26.5 & 39.7 & 3 & 27.1 & 31.6 & 41.3 & 2 & 51.0 & 30.1 & 18.9 \\
Richest & 3 & 30.6 & 34.6 & 34.8 & 2 & 36.1 & 28.6 & 35.3 & 2 & 47.1 & 27.4 & 25.5 \\
Richest & 3 & 28.6 & 34.0 & 37.4 & 2 & 35.2 & 29.9 & 34.9 & 2 & 51.0 & 27.0 & 22.0 \\
\hline Age difference & & & & & & & & & & & & \\
Wife Older & 3 & 29.9 & 29.8 & 40.3 & 4 & 37.4 & 23.3 & 39.3 & 2 & 55.2 & 27.6 & 17.2 \\
Same age & 3 & 37.5 & 18.0 & 44.4 & 3 & 31.1 & 21.7 & 47.2 & 2 & 69.0 & 23.4 & 7.6 \\
Wife younger & 3 & 30.9 & 30.4 & 38.7 & 3 & 29.0 & 30.6 & 40.4 & 2 & 45.7 & 30.8 & 23.6 \\
\hline Husband takes & & & & & & & & & & & & \\
No & 3 & 31.4 & 29.7 & 38.9 & 3 & 31.4 & 28.5 & 40.1 & 2 & 48.6 & 33.3 & 18.1 \\
Yes & 3 & 29.1 & 32.1 & 38.8 & 3 & 30.5 & 32.7 & 36.9 & 2 & 47.1 & 28.1 & 24.9 \\
\hline Husband Jealous & & & & & & & & & & & & \\
No & 3 & 27.9 & 31.9 & 40.2 & 3 & 29.7 & 25.9 & 44.5 & 2 & 45.9 & 29.5 & 24.6 \\
Yes & 3 & 31.2 & 30.4 & 38.4 & 3 & 31.4 & 32.7 & 35.9 & 2 & 48.5 & 30.9 & 20.6 \\
\hline Total & 3 & 30.4 & 30.7 & 38.8 & 3 & 30.9 & 30.7 & 38.4 & 2 & 47.8 & 30.5 & 21.7 \\
\hline
\end{tabular}

FDV First Forced Sex *Age in years Analysis restricted to 7002 ever married women wo had experienced counties except between place of residence in Mozambique (Figures 1, 2, and 3).

Figure 2: Kaplan Meier Probability Plots of Timing of first domestic violence among ever-married women in Kenya 
Table 3 shows the unadjusted (crude) determinants of the timing of first domestic violence after marriage among ever-married women in the three countries. The risk of experiencing domestic violence among ever-married women was significantly higher among separated/divorced and widowed women than currently married women across the three countries $(\mathrm{HR}=3.467 ; 95 \%$ $\mathrm{CI}=3.022-3.979 ; \quad \mathrm{HR}=1.847: 95 \% \mathrm{CI}=1.582-2.154$ and $\mathrm{HR}=1.747: 95 \% \mathrm{CI}=1.469-2.077$ for Nigeria, Kenya and Mozambique respectively). The risk of domestic violence was higher among younger ever-married women compared with those aged 35-49 years in the three countries. For instance, the risk among women aged 20-24 years in Nigeria, Kenya and Mozambique were about $50 \%$ times higher than the risk among women aged $45-49$ years.

In Nigeria, ever-married women living in urban areas have $14 \%$ higher risk of experiencing domestic violence compared to their rural counterparts $(\mathrm{HR}=1.138$ : 95\% $\mathrm{CI}=1.059-1.232)$. Compared with ever-married women with no formal education, the risk of domestic violence increased with increasing level of educational attainment except among those that had higher education in the three countries. The risks were 2.6, 2.5 and 1.3 times higher among ever-married women with primary, secondary and higher education in Nigeria respectively $(\mathrm{HR}=2.568 ; 95 \%$ $\mathrm{CI}=2.344-2.815 ; \quad \mathrm{HR}=2.461: \quad 95 \% \quad \mathrm{CI}=2.250-2.692 \quad$ and $\mathrm{HR}=1.282 ; 95 \% \quad \mathrm{CI}=1.090-1.507)$ respectively. The employed women in the three countries had significantly higher risks of domestic violence. For instance the risks were 1.5 times higher in Kenya and Nigeria and 1.2 times higher in Mozambique. The risk of first domestic violence appeared to increase with higher wealth quintiles in Nigeria but the reverse was the case in Mozambique while women from households in the richest wealth quintiles in Kenya had 35\% times lower risk of experiencing domestic violence compared with those in the poorest category $(\mathrm{HR}=0.647: 95 \% \mathrm{CI}=0.536-0.782)$. Women whose husbands take 
308 alcohol and get jealous when the woman talks to another man were more than double likely to first

309 have the risk of domestic violence than others across the three countries.

310 Table 3: The unadjusted determinants of domestic violence after marriage

\begin{tabular}{|c|c|c|c|}
\hline \multirow{2}{*}{ Characteristics } & \multicolumn{3}{|c|}{ Unadjusted determinants (HR \&95\% CI) } \\
\hline & Nigeria & Kenya & Mozambique \\
\hline \multicolumn{4}{|l|}{ Age } \\
\hline $15-19$ & $1.196(0.972-1.470)$ & $1.227(0.744-2.024)$ & $1.392(1.066-1.817)$ \\
\hline $20-24$ & $1.311(1.167-1.472)$ & $1.601(1.351-1.897)$ & $1.524(1.291-1.800)$ \\
\hline $25-34$ & $1.331(1.230-1.440)$ & $1.199(1.069-1.344)$ & $1.189(1.041-1.358)$ \\
\hline $35-49$ & Reference & & \\
\hline \multicolumn{4}{|l|}{ Marital Status } \\
\hline Currently Married & Reference & & \\
\hline Widowed & $1.078(0.902-1.289)$ & $1.177(0.961-1.441)$ & $0.671(0.484-0.930)$ \\
\hline Separated/Divorced & $3.467(3.022-3.979)$ & $1.847(1.584-2.154)$ & $1.747(1.469-2.077)$ \\
\hline \multicolumn{4}{|l|}{ Residence } \\
\hline Urban & $1.138(1.059-1.223)$ & $0.879(0.787-0.981)$ & $1.203(1.068-1.354)$ \\
\hline \multicolumn{4}{|l|}{ Education } \\
\hline No education & Reference & & \\
\hline Primary & $2.568(2.344-2.815)$ & $1.325(1.148-1.531)$ & $1.183(1.043-1.342)$ \\
\hline Secondary & $2.461(2.250-2.692)$ & $1.049(0.880-1.250)$ & $1.258(1.039-1.523)$ \\
\hline Tertiary & $1.282(1.090-1.507)$ & $0.667(0.492-0.903)$ & $0.839(0.461-1.528)$ \\
\hline \multicolumn{4}{|l|}{ Husband education } \\
\hline No education & Reference & & \\
\hline Primary & $2.539(2.292-2.813)$ & $1.367(1.170-1.598)$ & $1.157(0.997-1.342)$ \\
\hline Secondary & $2.654(2.413-2.919)$ & $1.054(0.888-1.253)$ & $1.196(0.997-1.436)$ \\
\hline Tertiary & $1.709(1.509-1.936)$ & $0.719(0.559-0.924)$ & $0.691(0.416-1.145)$ \\
\hline \multicolumn{4}{|l|}{ Employment } \\
\hline Employed & $1.452(1.327-1.590)$ & $1.453(1.283-1.646)$ & $1.249(1.113-1.403)$ \\
\hline \multicolumn{4}{|l|}{ Husband employment } \\
\hline Employed & $0.964(0.709-1.312)$ & $1.202(0.809-1.785)$ & $1.162(0.826-1.634)$ \\
\hline \multicolumn{4}{|l|}{ Wealth Category } \\
\hline Poorest & Reference & & \\
\hline Poorer & $1.399(1.240-1.577)$ & $1.256(1.090-1.448)$ & $0.813(0.673-0.983)$ \\
\hline Middle & $1.772(1.577-1.991)$ & $1.101(0.947-1.280)$ & $0.811(0.673-0.977)$ \\
\hline Richest & $1.673(1.487-1.882)$ & $0.900(0.769-1.053)$ & $0.949(0.792-1.137)$ \\
\hline Richest & $1.587(1.406-1.791)$ & $0.647(0.536-0.782)$ & $0.998(0.836-1.192)$ \\
\hline \multicolumn{4}{|l|}{ Age difference } \\
\hline Wife Older & Reference & & \\
\hline Same age & $0.475(0.311-0.726)$ & $1.428(0.859-2.372)$ & $1.366(0.844-2.211)$ \\
\hline Wife younger & $0.509(0.391-0.662)$ & $1.475(0.992-2.193)$ & $1.352(0.996-1.837)$ \\
\hline \multicolumn{4}{|l|}{ Husband takes alcohol } \\
\hline Yes & $3.498(3.260-3.753)$ & $2.092(1.888-2.319)$ & $2.362(2.105-2.651)$ \\
\hline \multicolumn{4}{|l|}{ Husband Jealous } \\
\hline Yes & $2.299(2.123-2.490)$ & $2.682(2.394-3.005)$ & $2.284(2.017-2.588)$ \\
\hline
\end{tabular}

HR Hazard Ratio CI Confidence Interval

Table 4 shows the outcome of the multiple Cox proportional hazard model of the timing of first domestic violence in the three countries while controlling for confounders. The adjusted risk of first 
315 domestic violence after marriage was about 1.7, 1.5, and 1.6 times higher among ever-married women aged 15-19 years than women aged 45-49 years in Nigeria, Kenya and Mozambique respectively. Ever-married women aged 20-24 years in Kenya were about twice likely to fall a victim of domestic violence earlier $(\mathrm{HR}=1.937 ; 95 \% \mathrm{CI}=1.586-2.366)$ compared to age group 3549 years. The likelihood of an ever-married woman to have an earlier experience of domestic violence was significantly higher among separated/divorced women across the three countries than other women. (H.R=2.424: 95\% $\mathrm{CI}=1.962-2.995 ; \quad \mathrm{HR}=1.266: 95 \% \quad \mathrm{CI}=1.006-1.594$, and $\mathrm{HR}=1.445: 95 \% \mathrm{CI}=1.106-1.887$ for Nigeria, Kenya and Mozambique respectively). Nigeria, $(\mathrm{HR}=1.674: 95 \% \mathrm{CI}=1.453-1.929)$ compared with those with no formal education but education was not a significant prognostic factor in Kenya and Mozambique. Furthermore, Nigerian women whose husbands had some education were generally more likely to experience domestic violence than those with no formal education, women with higher education had lower risks $(\mathrm{HR}=0.655: 95 \% \mathrm{CI}=0.443-0.970)$ in Kenya but this was not significant in Mozambique. However, living in urban areas put women at higher risk of domestic violence.

Compared to the risks among ever-married women from households in the poorest wealth quintile, the richer the household from which a woman comes from the low in all the countries but this relationship was not significant in Mozambique. For instance women from richest households in Nigeria and Kenya had about 32\% and 30\% lesser risk of domestic violence than those from households in the poorest wealth quintiles respectively $(\mathrm{HR}=0.686: 95 \% \mathrm{CI}=0.572-0.822$ and $\mathrm{HR}=0.705 ; 95 \% \mathrm{CI}=0.533-0.933)$. While employment status of the husbands were insignificant in the three countries, employed women in Nigeria and Kenya had higher risks of domestic violence than the unemployed women. Also the adjusted risks of first domestic violence was higher among 
338 women whose husbands take alcohol and get jealous when the woman talks to another man across

339 board.

Table 4: The Adjusted determinants of Violence after marriage

\begin{tabular}{|c|c|c|c|}
\hline \multirow{2}{*}{ Characteristics } & \multicolumn{3}{|c|}{ Adjusted determinants of Violence } \\
\hline & Nigeria & Kenya & Mozambique \\
\hline \multicolumn{4}{|l|}{ Age } \\
\hline $15-19$ & $1.742(1.374-2.209)$ & $1.544(0.862-2.766)$ & $1.621(1.093-2.405)$ \\
\hline $20-24$ & $1.454(1.269-1.665)$ & $1.937(1.586-2.366)$ & $1.493(1.146-1.945)$ \\
\hline $25-34$ & $1.366(1.249-1.494)$ & $1.248(1.087-1.432)$ & $1.181(0.954-1.461)$ \\
\hline \multicolumn{4}{|l|}{$35-49$} \\
\hline \multicolumn{4}{|l|}{ Marital Status } \\
\hline Currently Married & Reference & & \\
\hline Widowed & $1.012(0.849-1.208)$ & $0.844(0.691-1.030)$ & $1.196(0.936-1.528)$ \\
\hline Separated/Divorced & $2.424(1.962-2.995)$ & $1.266(1.006-1.594)$ & $1.445(1.106-1.887)$ \\
\hline \multicolumn{4}{|l|}{ Residence } \\
\hline Urban & $1.040(0.945-1.144)$ & $0.990(0.853-1.149)$ & $1.361(1.066-1.738)$ \\
\hline \multicolumn{4}{|l|}{ Education } \\
\hline \multicolumn{4}{|l|}{ No education } \\
\hline Primary & $1.659(1.462-1.883)$ & $0.938(0.746-1.180)$ & $1.216(0.979-1.512)$ \\
\hline Secondary & $1.579(1.371-1.818)$ & $0.951(0.723-1.251)$ & $1.226(0.802-1.874)$ \\
\hline Tertiary & $1.126(0.902-1.406)$ & $0.826(0.525-1.298)$ & $1.567(0.553-4.442)$ \\
\hline \multicolumn{4}{|l|}{ Husband education } \\
\hline No education & $1.650(1.440-1.891)$ & $1.102(0.868-1.399)$ & $1.047(0.821-1.336)$ \\
\hline Primary & $1.674(1.453-1.929)$ & $0.829(0.631-1.090)$ & $0.944(0.661-1.349)$ \\
\hline Secondary & $1.426(1.196-1.699)$ & $0.655(0.443-0.970)$ & $0.566(0.220-1.452)$ \\
\hline \multicolumn{4}{|l|}{ Tertiary } \\
\hline \multicolumn{4}{|l|}{ Employment } \\
\hline Employed & $1.27(1.145-1.408)$ & $1.340(1.144-1.569)$ & $1.015(0.845-1.218)$ \\
\hline \multicolumn{4}{|l|}{ Husband } \\
\hline Employed & $1.034(0.72-1.485)$ & $1.141(0.682-1.908)$ & $0.657(0.424-1.017)$ \\
\hline \multicolumn{4}{|l|}{ Wealth Category } \\
\hline \multicolumn{4}{|l|}{ Poorest } \\
\hline Poorer & $0.985(0.862-1.126)$ & $1.133(0.940-1.366)$ & $0.802(0.617-1.042)$ \\
\hline Middle & $0.851(0.736-0.983)$ & $1.016(0.832-1.242)$ & $0.878(0.676-1.141)$ \\
\hline Richest & $0.697(0.595-0.817)$ & $0.883(0.707-1.103)$ & $0.852(0.633-1.153)$ \\
\hline Richest & $0.686(0.572-0.822)$ & $0.705(0.533-0.933)$ & $0.815(0.536-1.237)$ \\
\hline \multicolumn{4}{|l|}{ Age difference } \\
\hline Wife Older & $0.495(0.316-0.777)$ & $1.806(0.998-3.269)$ & $1.010(0.475-2.150)$ \\
\hline Same age & $0.581(0.440-0.765)$ & $1.680(1.039-2.718)$ & $1.201(0.745-1.934)$ \\
\hline \multicolumn{4}{|l|}{ Wife younger } \\
\hline \multicolumn{4}{|l|}{ Husband takes } \\
\hline Yes & $2.789(2.557-3.042)$ & $1.936(1.708-2.194)$ & $2.615(2.176-3.144)$ \\
\hline \multicolumn{4}{|l|}{ Husband Jealous } \\
\hline Yes & $2.381(2.180-2.600)$ & $2.252(1.976-2.567)$ & $2.493(2.038-3.050)$ \\
\hline
\end{tabular}


343 While violence is a public health problem both in the developed and the developing countries.

344 Females, particularly the younger girls, are the most vulnerable population subgroups since they

345 are daily exposed and victimized by family members, at school, at work etc. It is more worrisome

346 in the developing countries due to either non-availability of strict punishment or failure to

347 implement the laws. Forced sex affects women of all ages across different socio-cultural

348 boundaries. This study sought to determine the time at which women in Kenya, Zimbabwe and

349 Cote d'Ivoire experience forced sex for the first time and the various factors influencing the timing

350 of the first occurrence.

351 There is no sign that domestic violence is reducing in Africa. In fact, it seems to have defiled every

352 intervention targeted at curtailing the menace in Africa. The prevalent socio-cultural belief in

353 Africa that a man is the head of his family and is at liberty to discipline erring wife might have

354 jeopardized efforts aimed at stalling domestic violence in sub-Sahara Africa. Domestic violence

355 takes many forms including physical, sexual, emotional, and mental. While studies abate on the

356 prevalence of domestic violence in marriages, there has been paucity of information on how soon

357 a married women experience domestic violence after marriage. Neither has there been adequate

358 information on the factors affecting the timing. The current study assessed the timings, identified

359 the risk factors, compared the timings among those currently married and formerly married and

360 also determined whether there are generational changes in the timing of first occurrence of

361 domestic violence among ever-married women in three sub-Saharan countries.

362 We found that the timings of first violence were significantly influenced by the age of women

363 (used as a proxy for birth cohorts), place of residence, women's and husbands' educational

364 attainment and the households from which a woman comes from. Most dazzling among our finding

365 is that more women born in the 1990s are experiencing domestic violence earlier in their marriage 
366 than those born 30 or 40 years earlier. We found a clear generational change in the time of first

367 domestic violence among the cohorts of births with higher risk among younger ever-married

368 women.

369 It is also a source of concern that the risk of domestic violence was significantly higher among the

370 separated and divorced women than among the widows and among the currently married women.

371 It has been reported in multiple studies that occurrence of violence against women is still high in

372 the sub-Saharan Africa region, particularly in Nigeria which is the most populous country in

373 Africa(12,13,22). Results from a recent study revealed that the total prevalence of spousal violence

374 (physical, sexual or emotional) is about $30.5 \%$ in Nigeria $45.3 \%$ in Kenya and $45.5 \%$ in

375 Mozambique(4).

376 The alarming rate of domestic violence in Africa remains an issue of concern. Despite the efforts

377 geared toward reducing the prevalence, significant change has not been recorded over the years.

378 In this study, the prevalence of domestic violence in Nigeria, Kenya and Mozambique are 12.3,

$3797.5 \%$, and $15.9 \%$ respectively. This shows an insignificant improvement in unhealthy sociocultural

380 norms that presupposes Nigerian women as inferior to men despite the development of gender

381 policy in Nigeria to promote the health and rights of women.

382 The known associated factors responsible for high rate of domestic violence are age, education,

383 employment, wealth status among others(19,31). The result of this study revealed that domestic

384 violence was very evident among ever-married women of ages 15-19, 20-24, $25-29$ and 30-34

385 years in Nigeria, Kenya and Mozambique. This is in consonance with a recent who multi-regional

386 study which showed high prevalence of IPV among ever-married women across the earlier

387 mentioned age groups. More importantly, this study agrees with the fact that IPV starts early in 
life (significantly high in age group 15-19) as suggested by the WHO multi-regional study(10). However, in this study, the highest report of domestic violence experience was found among respondents aged 20-24 (12\%, 7\% and 18\% in Nigeria, Kenya and Mozambique respectively) as opposed to age 40-44(37.8\%) in the multi-regional study. Similarly, a prior research showed that women younger than age 31 are more probable to report past year spousal violence(31).

In our study, the association between violence and employment across the three countries was not striking enough, although highest violence prevalence was reported among women in the Agricultural sector while professional employment appeared to be protective of violence particularly in Mozambique. Prior studies have suggested that employment is significantly associated with the risk of domestic violence(32).

Besides, low or no literacy of women have been found by prior studies to be a predictor of violence while higher education, at least secondary school education have been found to be protective of violence $(19,31,33,34)$. This is similar to what was found in this study - lower education of respondents and their partners seemed to increase the risk of violence across the three countries, suggesting that investing in education, especially women's education may reduce the incidence of violence in sub-Saharan Africa. Notably, lower risks of violence was associated with higher education in Kenya, Mozambique and Nigeria. More so, higher education was found to be protective of violence in Kenya and Mozambique. However, respondents with secondary education had higher risk of violence than those with primary education in Nigeria. This mild difference may be indicative of cultural differences.

Another interesting finding is that rural residence was protective of violence among ever-married women in Nigeria. Whereas, in a study carried out in South India, higher prevalence of violence was associated with rural residence suggesting that the effect of location(urban and rural) on 
411 violence may be subject to regional differences(35). Furthermore, Women in the poorest wealth

412 quintile had higher risk of violence in Nigeria, Kenya and Mozambique as opposed to prior multi-

413 country study from sub-Saharan Africa which indicated that higher prevalence of violence was

414 linked with higher household wealth quintile in Mozambique(4).

415 The observed level of domestic violence in this analysis might indicate that response to several

416 campaigns against violence against women is still poor in African countries. Although,

417 governments of different countries of Africa as the case in Nigeria have made several policies to

418 curb violence against women, it seems the implementation of such policies is still far below the

419 expectation. Even the calls by several non-governmental organizations advocating for "no violence

420 against women" do not appear being effective yet. It is therefore important for policy makers to

421 design a well implemented interventions that will promote peaceful cohabitations among

422 domestics in Africa.

423 Our findings have some limitations. The census cannot be entirely replaced by the NDHS data and

424 thus, there might still be some variations in the observed response. The question about the first

425 experience of violence after marriage is prone to recall bias and sometimes, the information

426 provided may not be absolutely correct. It would also have been useful to analyze the role of

427 respondents' behavior in the action of their partners against them. Although never-married women

428 were excluded in the analysis, this exclusion is nevertheless not suggestive of nonexistence of

429 physical or sexual violence among never-married women.

430 Despite all these limitations, this study has a significant message for policy against domestic

431 violence in Africa. Firstly, the analysis clearly showed that a large number of women in Nigeria,

432 Kenya and Mozambique are experiencing violence after marriage, which has led to dissolution of 
433 unions, disabilities and even deaths in many instances. Secondly, the residential variations in the

434 experience of violence and other relevant factors will assist policy makers in identifying gaps in

435 current programs geared towards preaching against violence in marriages and also guide

436 development partners to identify critical groups among the ever-married women for their

437 interventions.

438 The disparities in the effect of household income on the prevalence of domestic violence in

439 Mozambique and Kenya is an indication that addressing household-poverty may not automatically

440 aid the elimination of domestic in sub-Saharan(4), rather a wholesome approach must be taken to

441 combat the menace.

443 CONCLUSION

444 Domestic violence was quite high among ever-married women in Nigeria, Kenya and

445 Mozambique. Higher prevalence of violence was among those no longer living with partner

446 compared to those still with partner. Different socio-demographic characteristics (of the victim

447 and the perpetrator) are directly associated with the problem, especially, education, age and wealth

448 quintile. We therefore recommend that policy makers, government and other relevant stakeholders

449 from the private sector should establish effective strategies towards minimizing the identified risk

450 factors in order to reduce and prevent spousal violence as well as promote the health and wellbeing

451 of women.

\section{Ethical approval}

453 Ethical approval was sought from the National Health Research ethics committees in all the three 454 countries by the data originators and granted before starting the survey. Also, informed consents 
bioRxiv preprint doi: https://doi.org/10.1101/524637; this version posted January 19,2019 . The copyright holder for this preprint (which was not certified by peer review) is the author/funder, who has granted bioRxiv a license to display the preprint in perpetuity. It is made available under aCC-BY 4.0 International license.

455 were received from the participants before interviewing them. We obtained the approval from

456 Measure of DHS for permission to use the data before analysis. 


\section{REFERENCES}

1. Mayhew S WC. Global rhetoric and individual realities: linking violence against women. Cambridge, Cambridge University Press. 2002;159-80.

2. Campbell J. The health consequences of intimate partner violence. Lancet. 2002;359:150914.

3. Daher M. World report on violence and health. J Med Liban. 2002;51(2):59-63.

4. Bamiwuye SO, Odimegwu C. Spousal violence in sub-Saharan Africa : does household poverty-wealth matter? 2014;1-10.

5. WHO. World Health Organization (WHO): Global and regional estimates of violence against women: prevalence and health effects of intimate partner violence and non-partner sexual violence. WHO. 2013. 2013;

6. Garcia-Moreno C, Jansen H a FM, Ellsberg M, Heise L, Watts CH. Prevalence of intimate partner violence: findings from the WHO multi-country study on women's health and domestic violence. Lancet. 2006;368:1260-9.

7. National Gender Policy. Nigerian Federal Ministry of Women's Affairs and Social Development. Abuja, Nigeria: FMWA\& SD 9. 2006.

8. Bola SL. Spousal violence and pregnancy termination among married women in Nigeria. 2016;16(2):429-40.

9. García-Moreno C; Watts C, AIDS. Violence against women: its importance for HIV/AIDS. 2000;14(suppl3):S253-65.

10. World Health Organization. Global and regional estimates of violence against women: prevalence and health effects of intimate partner violence and non-partner sexual violence. 2013. 2013;57.

11. Heise L G-MC. Intimate partner violence. In Krug et al., eds. World report on violence and health. Geneva, World Health Organization,. 2002.

12. Roman N V., Frantz JM. The prevalence of intimate partner violence in the family: A systematic review of the implications for adolescents in Africa. Fam Pract. 2013;30(3):256-65.

13. Oyediran K., Isiugo-Abanihe U.C. Perception of Nigerian women on domestic violence: evidence from 2003 Nigeria demographic and health survey. Afr J Reprod Heal. 2005;9(2):38-53.

14. Antai DE, Antai JB. Attitudes of women toward intimate partner violence: a study of rural women in Nigeria. Rural Remote Heal. 2008;8(3):996.

15. Devries KM, Mak JY, García-Moreno C, Petzold M, Child JC, Falder G, Lim S, Bacchus LJ, Engell RE, Rosenfeld L, Pallitto C, Vos T, Abrahams N WC. Global health. The global prevalence of intimate partner violence against women. Science. 2013;340(6140):1527-8.

16. Zakar R, Zakar MZ, Mikolajczyk R, Krämer A. International Journal of Gynecology and 
Obstetrics Intimate partner violence and its association with women's reproductive health in Pakistan. Int J Gynecol Obstet. 2012;117(1):10-4.

17. Fagbamigbe AF, Adebowale AS, Morhason-Bello IO. Survival analysis of time to uptake of modern contraceptives among sexually active women of reproductive age in Nigeria. BMJ Open [Internet]. 2015 Jan 15 [cited 2016 Jan 12];5(12):1-8. Available from: http://bmjopen.bmj.com/cgi/content/long/5/12/e008371

18. Salazar M, San Sebastian M. Violence against women and unintended pregnancies in Nicaragua: A population-based multilevel study. BMC Womens Health. 2014;14(1):1-9.

19. Thomson DR, Bah AB, Rubanzana WG, Mutesa L. Correlates of intimate partner violence against women during a time of rapid social transition in Rwanda: Analysis of the 2005 and 2010 demographic and health surveys. BMC Womens Health. 2015;15(1):1-13.

20. Pollitt CC, García-Moreno C, Jansen HA, Heise L E, M, Watts C et al. Intimate partner violence, abortion, and unintended pregnancy: results from the WHO Multi-country Study on Women's Health and Domestic Violence. Obs Int J Gynaecol. 2013;120:3-9.

21. Begum S, Dwivedi SN, Pandey A MS. Association between domestic violence and unintended pregnancies in India: Finding from NFHS-2 data. Natl Med J India. 2010;23:137-9.

22. Goo L; Harlow SD. Intimate partner violence affects skilled attendance at most recent delivery among women in Kenya. Matern Child Heal J. 16(5):1131-7.

23. Abuya BA; Onsomu EO; Moore D \& Piper CN. Association between education and domestic violence among women being offered an HIV test in urban and rural areas in Kenya. J Interpers Violence. 27(10):2022-38.

24. Okenwa L; Lawoko S; Jansson B. Contracep- tion, reproductive health and pregnancy outcomes among women exposed to intimate partner violence in Nigeria. Eur J Reprod Heal Care. 2011;16(1):18-25.

25. Wong JYH, Choi AWM, Fong DYT, Choi EPH, Wong JKS, So FL, et al. A comparison of intimate partner violence and associated physical injuries between cohabitating and married women: A 5-year medical chart review. BMC Public Health. 2016;16(1):1-9.

26. Umana JE, Fawole OI, Adeoye IA. Prevalence and correlates of intimate partner violence towards female students of the University of Ibadan, Nigeria. 2014;

27. Abramsky T, Watts CH, Garcia-moreno C, Devries K, Kiss L, Ellsberg M, et al. What factors are associated with recent intimate partner violence ? findings from the WHO multicountry study on women' s health and domestic violence. BMC Public Health. 2011;11(1):109.

28. Olayanju L, Naguib RNG, Nguyen QT, Bali RK, Vung ND. Combating intimate partner violence in Africa: Opportunities and challenges in five African countries. Aggress Violent Behav. 2013;18(1):101-12.

29. Oladepo O, Yusuf OB, Arulogun OS. Factors Influencing Gender Based Violence Among Men and Women in Selected States in Nigeria. Afr J Reprod Health. 2011;15(4):78-86. 
536 30. National Population Commission (Nigeria) and ICF International. Nigeria Demographic 537 and Health Survey 2013. Abuja, Nigeria; 2014.

538 31. Eldoseri HM, Sharps P. Risk Factors for Spousal Physical Violence Against Women in $539 \quad$ Saudi Arabia. J Interpers Violence. 2017;1.

540 32. Semahegn A, Mengistie B. Domestic violence against women and associated factors in 541 Ethiopia; Systematic review. Reprod Health. 2015;12(1).

542 33. Umubyeyi A, Mogren I, Ntaganira J, Krantz G. Women are considerably more exposed to 543 intimate partner violence than men in Rwanda: Results from a population-based, cross$544 \quad$ sectional study. BMC Womens Health. 2014;14(1):1-12.

545 34. Leite FMC, Amorim MHC, Wehrmeister FC, Gigante DP. Violence against women, $546 \quad$ Espírito Santo, Brazil. Rev Saude Publica. 2017;51:33.

547 35. George J, Nair D, Premkumar N, Saravanan N, Chinnakali P, Roy G. The prevalence of 548 domestic violence and its associated factors among married women in a rural area of 549 Puducherry, South India. J Fam Med Prim Care. 2016;5(3):672. 

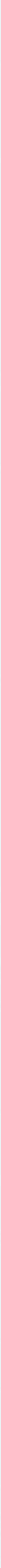

Figure 3 